\title{
Numerical analysis of bevel gear forming
}

\author{
Jaroslaw Bartnicki ${ }^{1}$ \\ ${ }^{1}$ Lublin University of Technology 38D Nadbystrzycka, 20-618 Lublin, Poland
}

\begin{abstract}
In this paper the numerical analysis of bevel gear forming is presented. Simulations are made by means of FEM using Deform 3D software. Distributions of stress, strain, temperature and Cockroft - Latham damage criterion are presented at various process parameters. Obtained shape of final part and calculated loads during the process course can be useful for the further industrial applications.
\end{abstract}

\section{Introduction}

The problematic of different mechanical elements with teeth forming is really complex. Among several manufacturing technologies there is a choice between machining or metal forming methods. Rarely the casting technologies are applied, but their role begins to be marginal.

The choice between different machining technologies is connected with time of manufacturing, which is really the most important factor in cost calculation. Due to this reason, in wider scope of applications (especially in mass production) the metal forming technologies find their place.

The other requirements are also connected with different fields of applications as aviation or automotive industry with special norms concerning manufacturing methods. Presently, thinking about durability and elevated mechanical properties of different parts with teeth the forging or rolling processes are widely applied. In the case of forging technology many parts are formed as preform by rolling or forging. Finally these parts are forged with flash. In minority of forging plants forging with flash is replaced by process without flash. This tendency permits to reduce wastes and time loss due to additional flash trimming operation. The advantage of this process is also in continuity of material into the forging.

\section{Bevel gear forming}

\subsection{Traditional forging}

Presently in one of the Polish industry plant bevel gear part, presented in Figure 1, is traditionally forged in two operations. This automotive element is firstly prepared as cylindrical bar, which is heated and upset in the first operation. In the second operation it is possible to obtain final part with flash which is trimmed in additional stand. Normally, these kinds of parts are made in series between $10000-20000$ pieces on one command.

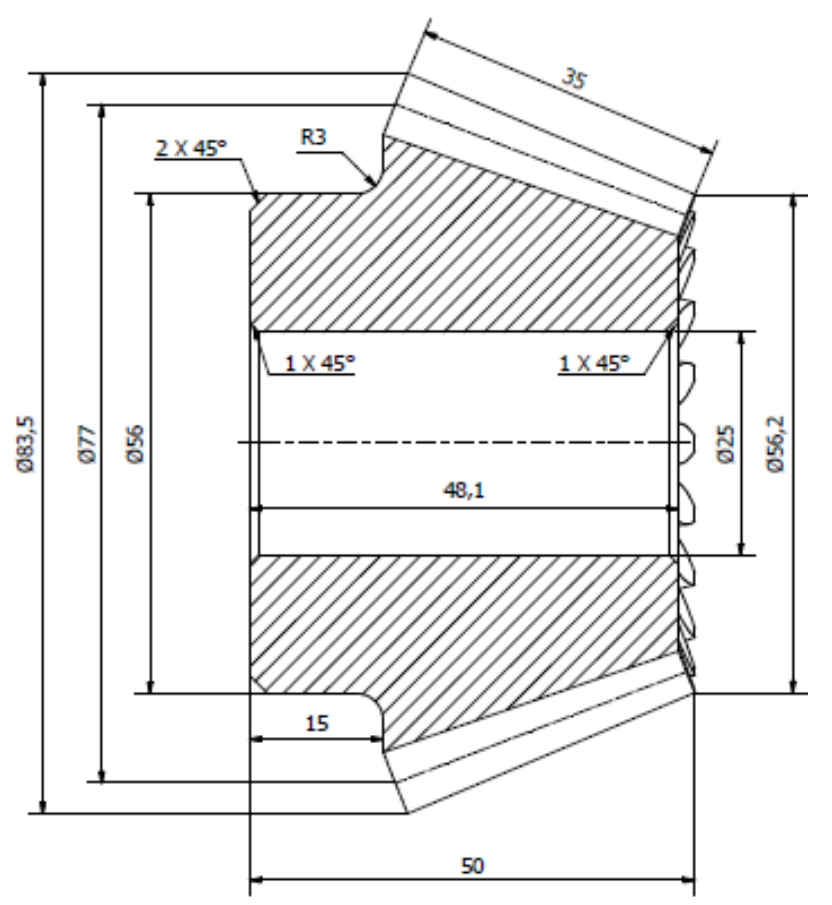

Figure 1. Schema of bevel gear.

This "traditional" forging technology has many advantages. Among them it is worth to notice that it is possible to apply bars or preforms with some height and diameter tolerances. The process can be realized using different machines - presses and hammers and obtained final parts have relatively good repeatability. This very important factor is connected with possible to obtain close manufacturing tolerances, which permit to decrease final machining of obtained bevel gears. Normally in the presented case the material allowances can be limited to $0.3-0.4 \mathrm{~mm}$. During machining, due to non continuous

${ }^{1}$ Corresponding author: j.bartnicki@pollub.pl 
contact between cutting blades of tools, in this case these allowances are bigger (usually about $0.8 \mathrm{~mm}$ ) This allows obtaining better machining conditions, limiting vibrations and increasing lifetime of machining tools [15].

\subsection{Proposed solution}

One of the biggest problems in industry is the proper choice of manufacturing technological parameters. The optimal range of forming forces, speeds and temperatures decide about costs and time of the proposed process. Parallely, the same rule have additional operations, which are also very important.

The modern forging technologies are focused on reduction of wastes, operations and operating time. One of the solutions for obtaining these gains concern close die forging technologies without flash, the second are connected with near net shape. The terms informs about very close to the final (net) shape of parts. It reduces, of course ,the need for surface finishing as machining or grinding. The proposition for bevel gear parts is the numerical calculations presented in this paper. Analysis concerns stage of preform manufacturing from upset cylindrical bar - shown in Figure 2 and final bevel gear forging -shown in Figure 3. The dies for final forging stage are presented in Figure 4.
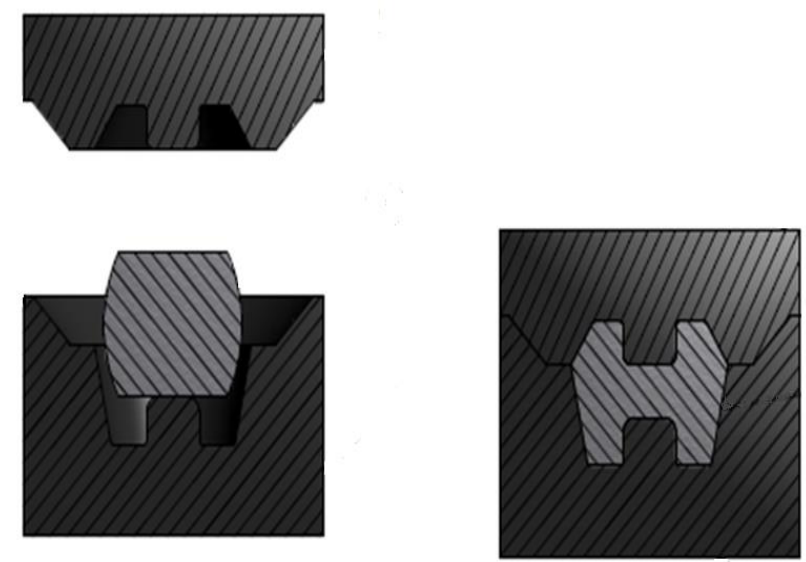

Figure 2. Preform forging from upset cylindrical bar (initial position and final stage)
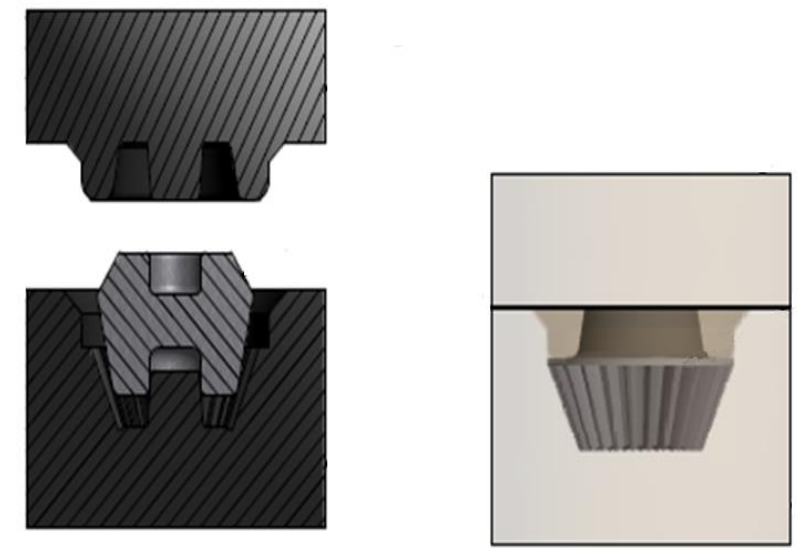

Figure 3. Final bevel gear forging from preform (initial position and final stage)
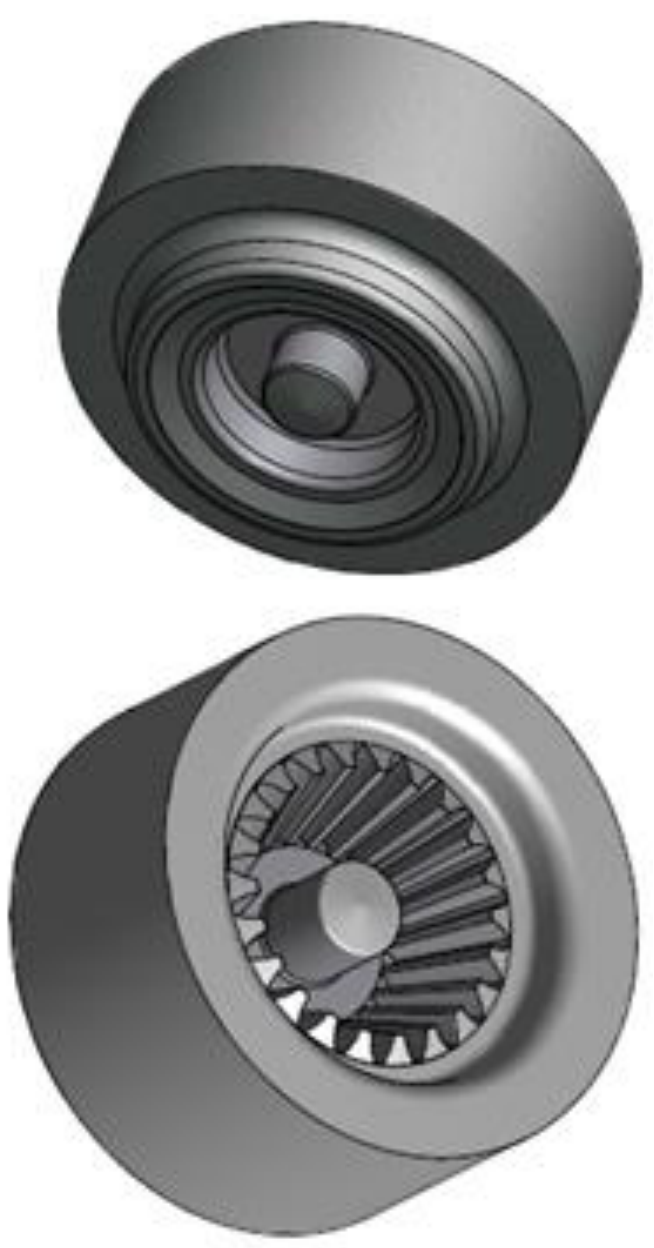

Figure 4. Final bevel gear dies: bottom die (left) and upper die (right)

\section{Numerical simulation}

\subsection{Software, process conditions and numerical model}

Numerical calculations of the close die forging without flash process of bevel gear realized with the application of software Deform3D, according to the model of final part given in Figure 5, were discussed. In order to achieve the result the most similar to the real one, it was decided that the process would take place in conditions of heat exchange with the environment. Material model of steel $20 \mathrm{MnCr} 5$ (Table 1) was taken from software library, modified and finally described as:

$$
\begin{gathered}
\sigma=3599.85 e^{-0.003 \cdot T} \varphi^{-4.7 \theta-05 \cdot T-0.043} . \\
e^{\left(\frac{-3.4 \theta-05 \cdot T-0.028}{\varphi}\right)} \phi^{(5.3 e-05 \cdot T+0.022)}
\end{gathered}
$$

where: $\sigma$ - flow stress; $\varphi$ - strain; $\dot{\varphi}-$ strain rate and $T$ - temperature.

The initial temperature of the billet was form the range between $(1000 \div 1150)^{\circ} \mathrm{C}$ with steps by $50^{\circ} \mathrm{C}$. The forming dies (modelled as rigid bodies) temperature was assumed $150^{\circ} \mathrm{C}$. The heat exchange coefficient between 
tools and the billet was assumed equal $4000 \mathrm{~W} / \mathrm{m}^{2} \mathrm{~K}$ and between the billet and the air it was $200 \mathrm{~W} / \mathrm{m}^{2} \mathrm{~K}$. Shear friction model with friction factor $\mathrm{m}=0.3-0.5$ was taken into account during calculations $[6,7]$.

Table 1. Chemical composition of $20 \mathrm{MnCr} 5$ steel

\begin{tabular}{|c|c|c|c|c|c|c|}
\hline $\mathrm{C}$ & $\mathrm{Si}$ & $\mathrm{Mn}$ & $\mathrm{Cr}$ & $\mathrm{Ni}$ & $\mathrm{Cu}$ & $\mathrm{P}$ \\
\hline 0.17 & 0.15 & 1.10 & 1.00 & $\mathrm{Max}$ & $\mathrm{Max}$ & $\mathrm{Max}$ \\
\hline 0.22 & 0.40 & 1.40 & 1.30 & 0.30 & 0.30 & 0.035 \\
\hline
\end{tabular}

Numerical model of the close die forging without flash was build into the Deform3D software. The workpiece was divided into 210000 tetrahedral elements. The automatically remeshing option was switched on with criterion of maximal effective strains. Due to this fact, very often remeshing calculations needs more time. Application of volume control option during forming and remeshing permits to preserve stable material volume. Without this option, during remeshing the proposed software systematically decreases material volume. In the case of close die forging without flash it would provoke infilling of dies, especially in the zones of created teeth. The initial position for final forging of bevel gear without flash is presented in Figure 6.

\subsection{Distribution of effective stress and strains}

Figure 7 presents the forming process with distributions of effective stress with process advancement given in percents. The maximum values of effective stress during this process reach the values about $(820-1350) \mathrm{MPa}$ at the area of contact tools - workpiece. After finishing of teeth forming, effective stresses values increase instantanely due to closed material volume between the dies. Considering the really high values of effective stresses inside the formed workpiece, it is possible to predict very high load on the dies surfaces. Especially, it can be dangerous near the spliting line between dies at the end of teeth forming areas. This fact can be unfavourable for the die durability due to risk of cracking initiation or faster wear usage with elevated temperature. Because of that, it is higly recommended in die manufacturing to make special pads with impressions segments, which allow to change these damaged elements very fast. The main problem in designing of this king of forging processes can be practical prevision of durability of impressions connected with machine characteristics, workpiece temperature and distributions of loads during forming [8].

Apart from the effective stress distribution into the workpiece and on the dies surfaces, distribution of strain in the final product is also the important factor. The fields of effective strains inform about material flow into the workpiece and show, for example possiblity of overlaping creation during the forging process. In the Figure 8 the distribution of effective strain in this process is shown. The highest values of effective strain are observed in the area of teeth forming and at the punches acting areas. The core of the formed part stays without strain, yet, it gives part rigidity. In the same cases of forming from tube shaped billets material flowed also into the billet axis, which disturbed final shape of obtained parts. Finally, all calculation cases were realized using full billets.

First simulations were made in the most favourable conditions recommended to these types of forging process designing. Friction factor $\mathrm{m}=0.3$ applied in this case was chosen basing on laboratory experiments and observations of industrial processes with different lubrications of dies surfaces.

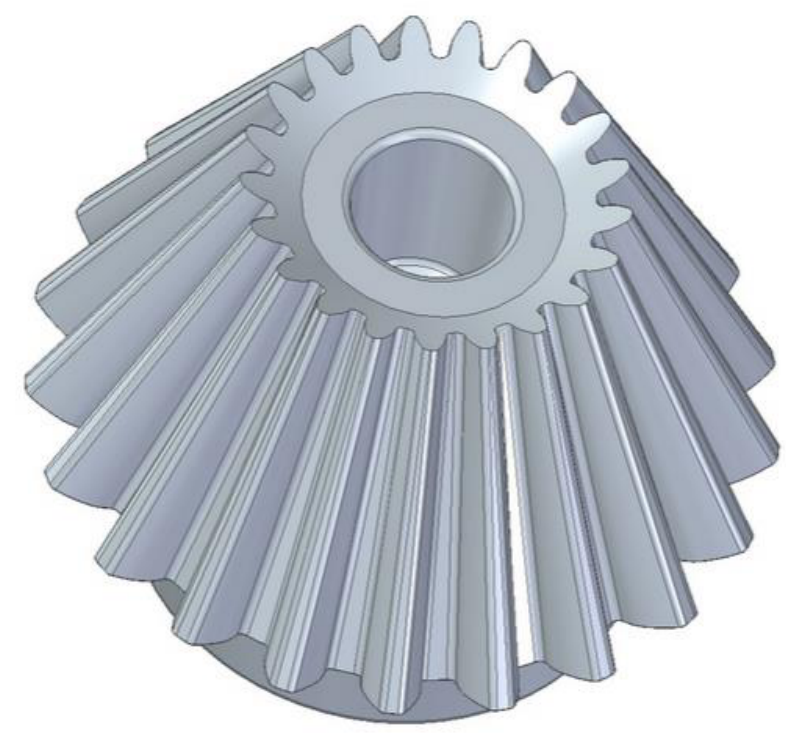

Figure 5. Bevel gear - model of final part.

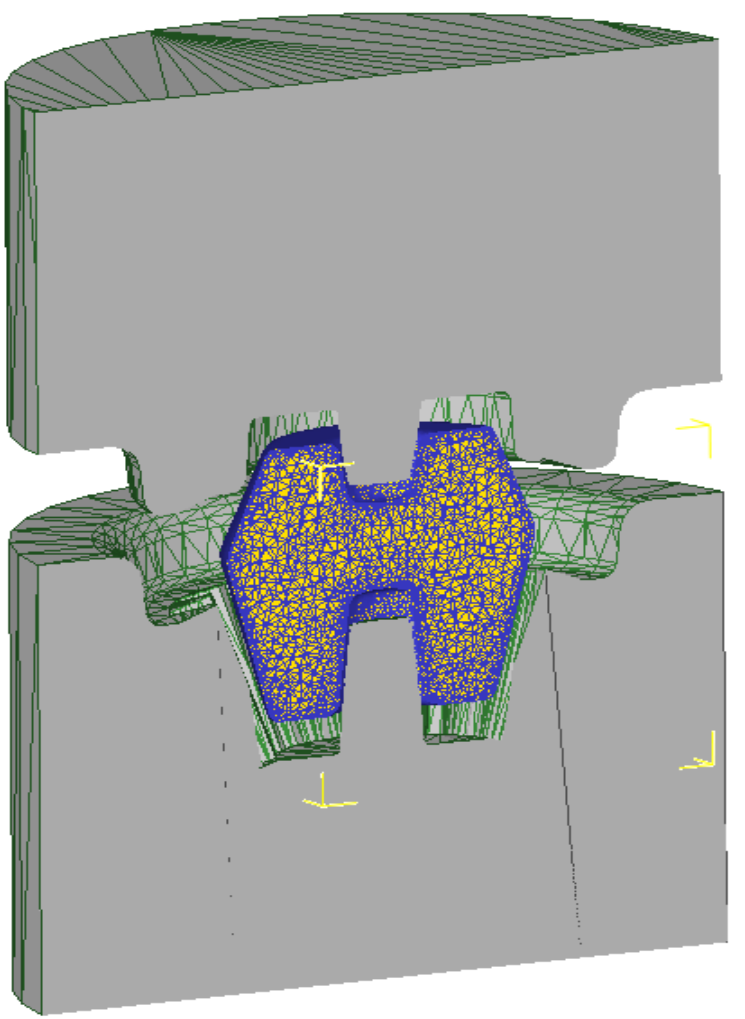

Figure 6. Numerical model of the bevel gear forging without flash and workpiece with initial mesh 

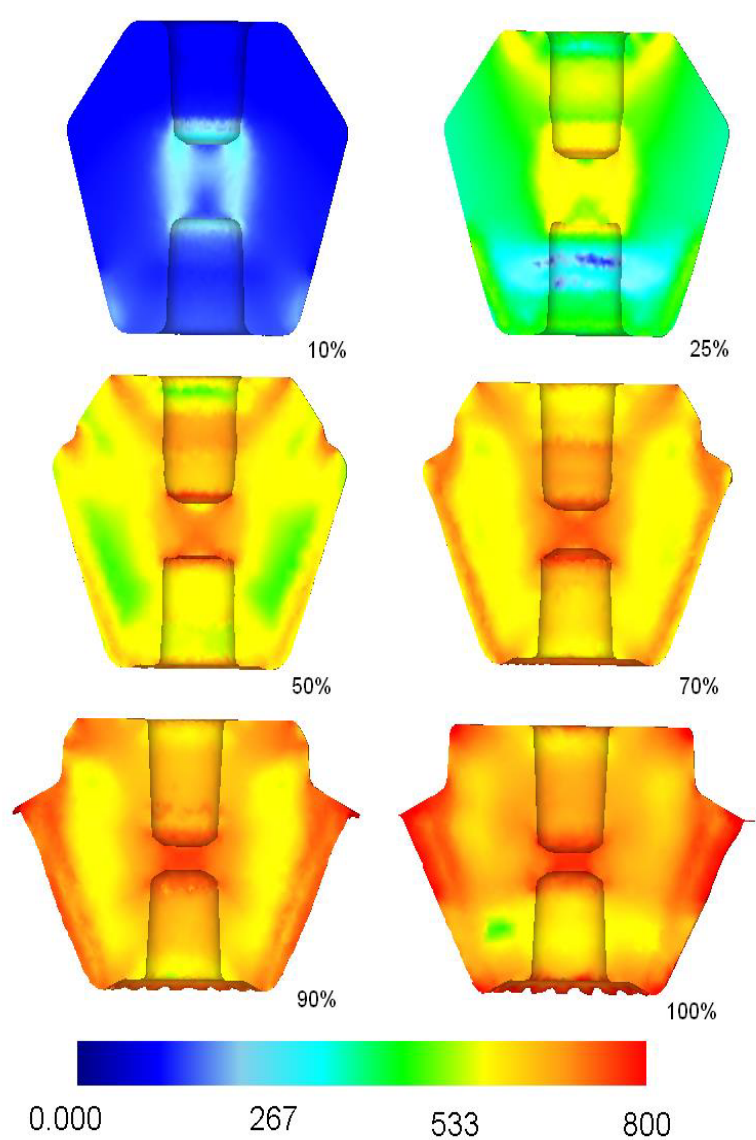

267

533

800

Stress - Effective (MPa)

Figure 7. Effective stress distribution during forging with initial temperature $1150^{\circ} \mathrm{C}$ and friction factor $\mathrm{m}=0.3$

\subsection{Influence of temperature range and friction factor values}

Presented in the Figure 7 and 8 distributions of effective stress and strains were obtained in the most favourable process conditions taken into consideration in assumptions. Beginning the process with recommended temperature of material $1150^{\circ} \mathrm{C}$ it was possible to finish forging at $940^{\circ} \mathrm{C}$. All forming cycle took 4,5 seconds, which was in accordance with industrial possibilities of the press proposed for this process. Changing the conditions as lowering the temperature of workpiece or taking into calculations dies with initial environment temperature $20^{\circ} \mathrm{C}$ can be dangerous for virtually designed impressions. For the initial workpiece temperature $1000^{\circ} \mathrm{C}$ the end of the forming process was calculated with temperature of the final part about $830^{\circ} \mathrm{C}$. At the same time, the effective stress into the final part reached $1350 \mathrm{MPa}$ and observed loads can be dangerous for dies impressions. In the Figure 9 and 10 distributions of effective stresses in workpiece during forming and loads on tools with different initial temperatures are shown. In all presented in this diagram effective stress distributions initial temperature of dies was $150^{\circ} \mathrm{C}$. The biggest values of effective stresses were noticed at the punch front area and near the biggest part's diameter. Analysing the process beginning with "cold" dies at $20^{\circ} \mathrm{C}$, the final temperature of the obtained bevel gear part will be relatively lower than in stable manufacturing stage. With the part temperature about $720^{\circ} \mathrm{C}$ (workpiece initial temperature in this case was $1000^{\circ} \mathrm{C}$ ) it is almost certain to damage fixed in the press tools. Applying during the forming process different friction factors allowed to verify the influence of lubrication on dies impressions filled by metal. Proposed to the simulations friction factor value $\mathrm{m}=0.3$ in all different temperatures variants was satisfactory and provided to obtain final part with correct shapes. Almost the same results were observed with the higher friction factor value $\mathrm{m}=0.4$. Comparing the same simulations steps, it was possible to observe a little slower filling of the dies impressions. Greater change was noticed with application of friction factor $m=0.5$. In this case it was really problematic to finish the process before final dies closing. Actually, it cannot be observed in practise because of constant material volume in all the analysed cases. However, in worked out simulations this observation informs about possible difficulties in real process without proper lubrication [9-10].
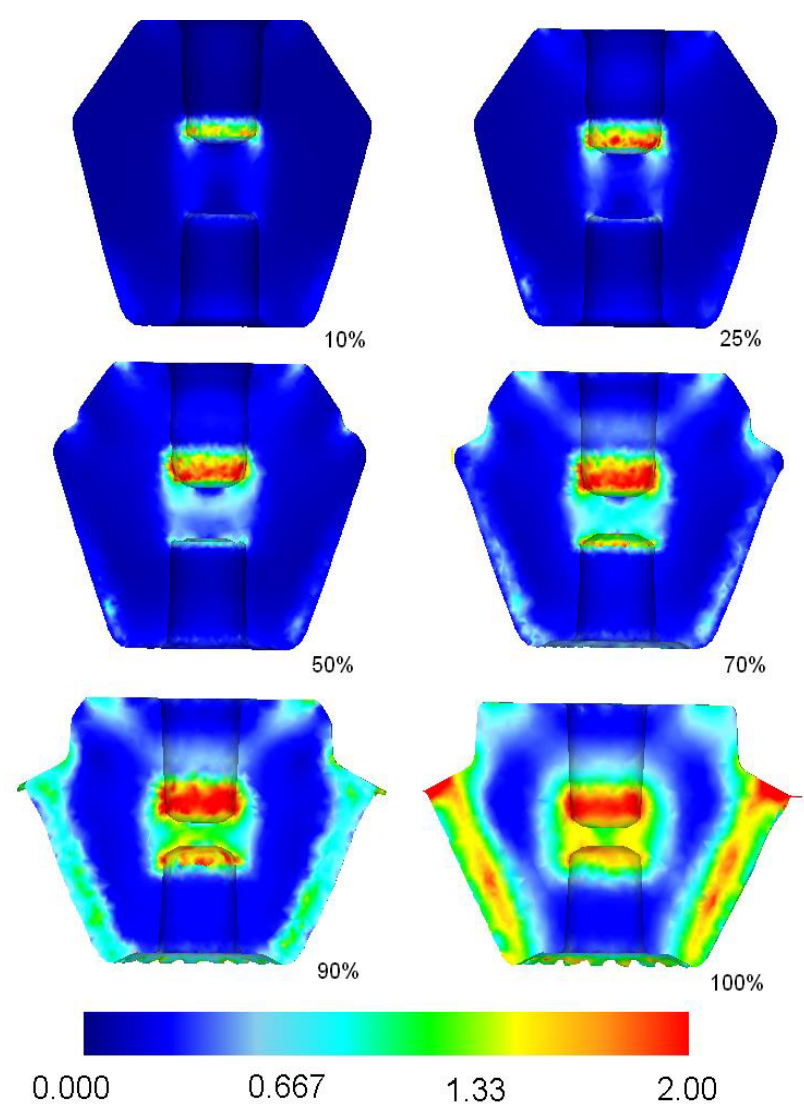

Strain - Effective $(\mathrm{mm} / \mathrm{mm})$

Figure 8. Effective strain distribution during forging with initial temperature $1150^{\circ} \mathrm{C}$ and friction factor $\mathrm{m}=0.3$

\subsection{Cockroft - Latham criterion}

During the calculation also the damage criterion was verified. In the Deform3D software there are several damage criteria but the most popular is Cockroft Latham integral, which calculated value informs about the risk of crack presence inside the formed part. 
Basing on experience and literature research it can be stated that in the case of hot metal forming conditions for steels during forging process accepted values of this integral are about $0.7-0.8$. In the Figure 11 , the results of numerical calculations using Cockroft-Latham integral at final simulations steps, are presented.

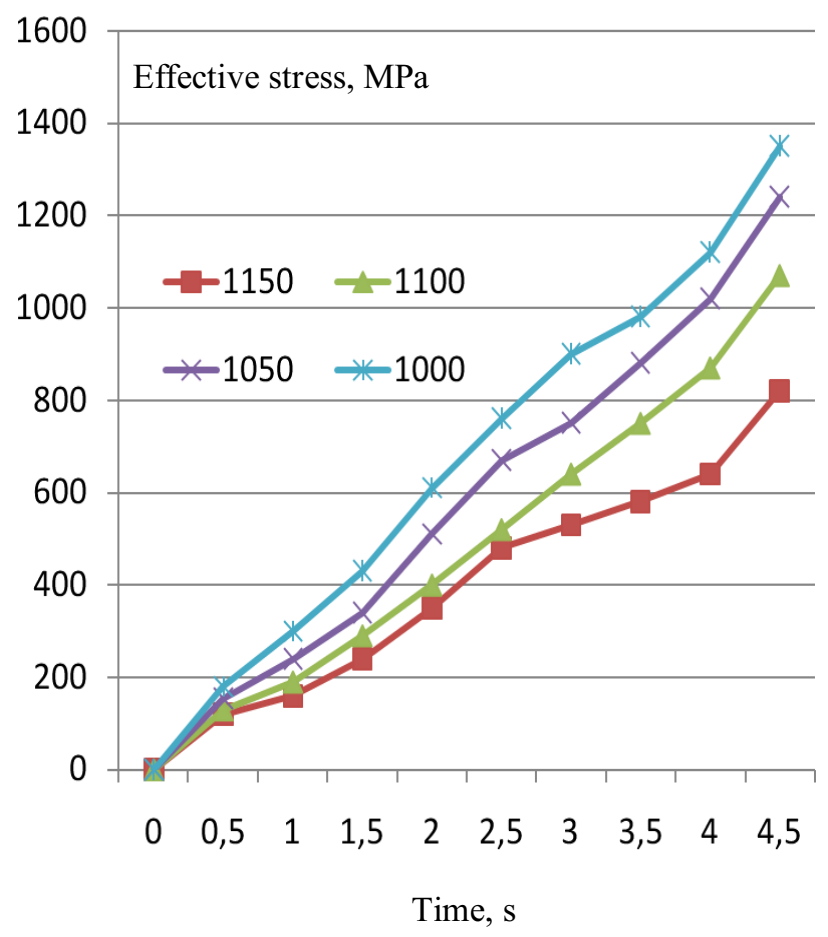

Figure 9. Effective stress distribution during forging with marked initial workpiece temperatures

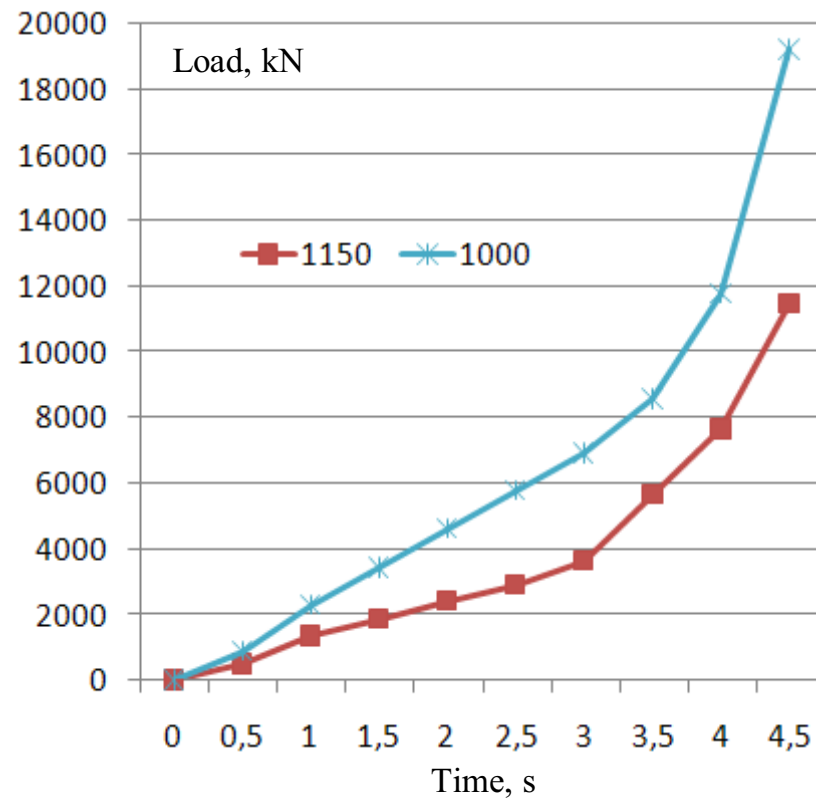

Figure 10. Loads on dies distribution during forging with marked initial workpiece temperatures

Observed distribution of Cockroft - Latham damage criterion allows for crack initiation predictions. In the most favourable composition of the highest initial temperature of workpiece and the lowest friction factor it can be possible to obtain part with relatively reduced risk of internal faults presence. But all changes of the mentioned above process parameters can disturb the process by increasing probability of internal cracks propagation. Due to this fact, all parts applied in automotive and aviation industry must be checked by non destructive tests. Presented simulations results showed only that the risk of part failure during manufacturing process is real and must be verified in laboratory and further industrial tests before application in manufacturing program of forging plant.

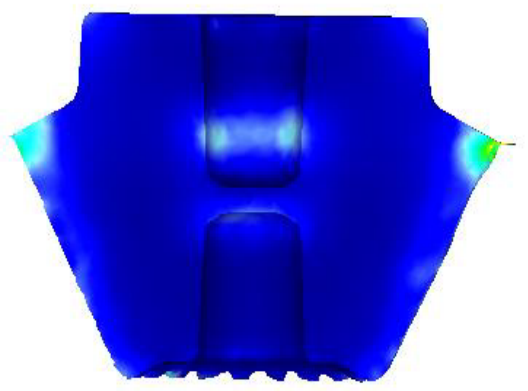

\section{Damage} 1.00

$m=0.3 T=1150$

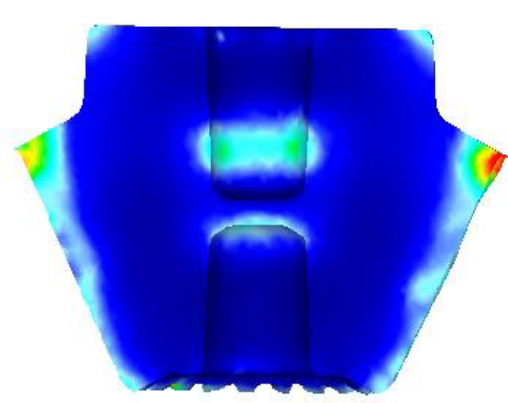

0.667

$m=0.3 T=1000$

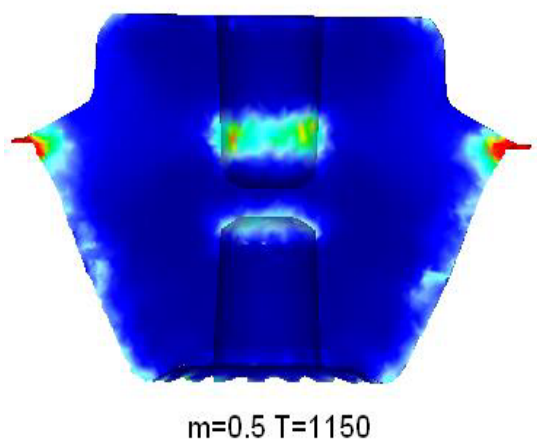

0.333

0.000

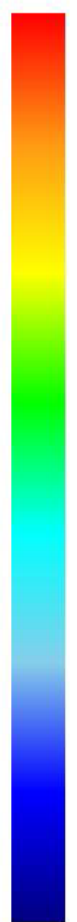

Figure 11. Cockroft - Latham integral values calculated in simulations realised with marked friction factors and initial workpiece temperatures

\section{Summary}

The conducted numerical calculations show the possibility of forming of bevel gear by means of close die forging without flash on parts from steel $20 \mathrm{MnCr} 5$. Presented in Figure 12 final shape of bevel gear part modelled as forging without flash show very close dimensional accuracy to the proposed model of the final part. Presented in this Figure teeth have a correct contour, which reflect die impressions. In many proposed solution the last stage of this kind of forming is additional sizing 
process. This operation permits to obtain straight surfaces and smaller material allowances. In practice ,before this operation additional heating is needed and the cost of this added energy is elevated in comparison with total cost of manufacturing process.

On the basis of the obtained numerical results, it was planned to make experiments in the hydraulic press, allowing for practical realization of laboratory tests for this kind of parts. The further works on determining the dependency between the process parameters and the achieved dimensional deviations of the formed products should lead to obtain products of shape close to the final outline.
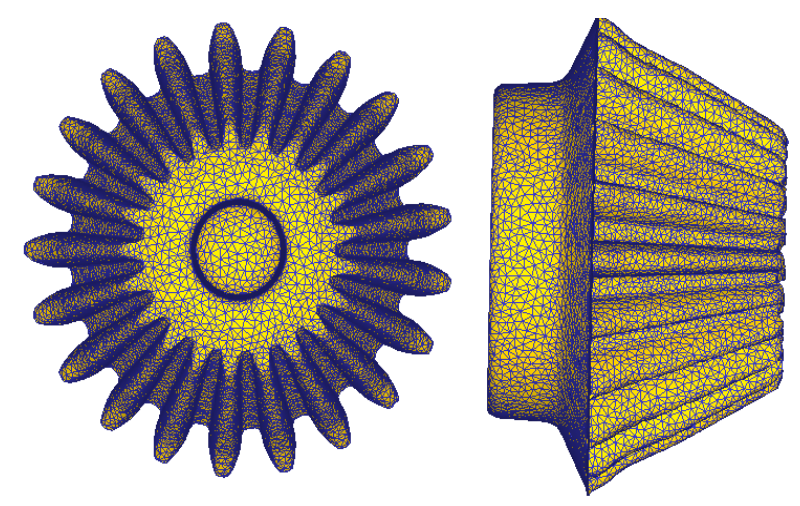

Figure 12. View of final shape of bevel gear part modelled as forging without flash

\section{References}

1. R. Glass, F. Hahn, M. Kolbe, L.W. Meyer, , Journal of Materials Processing Technology, 80-81, 174 (1998).

2. D. P. Townsend, Dudley's Gear Handbook-the Design, Manufacture, and Application of Gears, 2nd Ed., McGraw-Hill, New York, 1991

3. J. Bartnicki, J. Tomczak, Archives of Metallurgy and Materials, 60, 2739 (2015)

4. J. Bartnicki, J. Tomczak, Z. Pater Key Engineering Materials - 622-623,1215 (2014)

5. Z. Pater, J. Bartnicki, Metalurgija, 51, 501 (2012)

6. A. Stefanik, H. Dyja, P. Szota, S. Mróz, , Archives of Metallurgy and Materials, 56, 543 (2011).

7. Z. Pater, J. Tomczak, T. Bulzak, Metalurgija, 54, 419 (2015)

8. Jun-song Jin, Ju-chen Xia, Xin-yun Wang, Guo-an $\mathrm{Hu}$, Hua Liu, Journal of Central South University of Technology, 16, 546 (2009)

9. Z. Pater, A. Gontarz, A. Tofil, Journal of Shanghai Jiaotong University (Science), 16, 162 (2011)

10. A. Gontarz, A. Dziubińska, Ł Okoń, Archives of Metallurgy and Materials, 56, 379 (2011) 